\title{
O USO DO APLICATIVO WHATSAPP COMO RECURSO DIDÁTICO: UMA EXPERIÊNCIA NO ENSINO FUNDAMENTAL ANOS FINAIS
}

\section{The Use of The WhatsApp Application as a Teaching Resource: An Experience in Elementary Education Final Years}

\author{
Terezinha Marisa Ribeiro de Oliveira* \\ Carmem Lúcia Costa Amaral**
}

\begin{abstract}
Resumo: Este artigo tem como objetivo apresentar o resultado de uma pesquisa que teve como finalidade avaliar a contribuição do aplicativo WhatsApp no ensino de Matemática. Este aplicativo foi utilizado como recurso didático para o esclarecimento de dúvidas de conteúdos propostos nas atividades de lição de casa. Participaram dessa pesquisa 60 alunos de duas turmas do $9^{\circ}$ ano do Ensino Fundamental Anos Finais de uma escola pública da cidade de Votorantim (São Paulo). Os alunos criaram um grupo nesse aplicativo para discutir entre eles as dúvidas que foram surgindo durante a resolução da lição de casa. A professora também participou do grupo e das discussões, porém delimitou um horário para adequar tempo e espaço para não ter uma sobrecarga de trabalho. Os resultados mostraram que esse aplicativo, além de contribuir para a aprendizagem, melhorou a relação entre os alunos e a professora, auxiliou os mais tímidos, com dificuldades, a exporem suas dúvidas e a docente a perceber os erros conceituais em relação à Matemática. Desta forma, pode-se concluir que o uso desse aplicativo foi uma experiência exitosa, uma vez que os mesmos continuaram utilizando o grupo para tirar dúvidas sobre as atividades nas quais encontram dificuldades.
\end{abstract}

Palavras-chave: Ensino de Matemática. Tecnologias. Aplicativo WhatsApp.

Abstract: This article intends to present the result of a research whose aim was to evaluate the contribution of the WhatsApp application in Mathematics teaching. This App was used as a didactic resource to clear doubts on the content proposed in homework activities. Sixty students from two 9th-grade classes of Elementary School Final Years from a public school in Votorantim (São Paulo) took part in this research. In such App, the students created a group to discuss among themselves the doubts that appeared as they did their homework. The teacher also participated both in the group and in the discussions, but she set a schedule to adjust time and space so that there was not a work overload. The results showed that this App, in addition to contributing to learning, improved the relationship between students and the teacher, helped the most timid ones who had some difficulties to express their doubts and the teacher to perceive conceptual errors in relation to Mathematics. Thus, it can be concluded that the use of this

\footnotetext{
* Mestrado em Ensino de Ciências pela Universidade Cruzeiro do Sul, Doutoranda do PPG em Ensino de Ciências e Matemática da Universidade Cruzeiro do Sul. Professora de Matemática e Ciências na Secretaria de Educação do Estado de São Paulo. E-mail terezinha.marisa@gmail.com, Orcid: https://orcid.org/0000-0002-9064-8518.

** Graduação em Química pela Universidade Federal do Rio Grande do Norte, Mestrado em Química Orgânica pela Universidade de São Paulo e doutorado em Química Orgânica pela Universidade de São Paulo. Pesquisadora e Professora do PPG da Universidade Cruzeiro do Sul. E-mail: carmem.amaral@cruzeirodosul.edu.br. Orcid: https://orcid.org/0000-0002-6495-153X.
} 


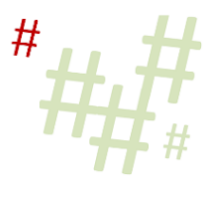

application was a successful experience, since they continued to use the group to clear doubts on the activities in which they find difficulties.

Keywords: Mathematics teaching. Technologies. WhatsApp application.

\section{Introdução}

Como professoras, temos observado ao longo de nossa prática pedagógica que a aprendizagem de Matemática sempre esteve atrelada à insegurança dos alunos em desenvolver seus conteúdos, o que pode levar a problemas emocionais como baixa autoestima e dúvidas de sua capacidade intelectual. Para eles, essa matéria é difícil e sua aprendizagem requer talento e aptidão para os números. Os discentes não percebem que para aprendê-la é preciso atenção, trabalho e dedicação, como qualquer outra disciplina.

Nas escolas do estado de São Paulo, por exemplo, o resultado da crença de que aprender Matemática é difícil tem refletido nos baixos índices do desempenho obtidos nas avaliações externas como Prova Brasil e Saresp (Sistema de Avaliação do Rendimento Escolar do Estado de São Paulo). Esses baixos índices de aprendizagem também foram detectados pelo Programa Internacional de Avaliação de Estudantes (PISA).

Os dados do PISA de 2018 mostraram que dois terços dos estudantes brasileiros de 15 anos têm um nível de aprendizado em Matemática mais baixo do que é considerado "básico" pela Organização para Cooperação e Desenvolvimento Econômico (OCDE). Os resultados dessa avaliação, que conta com a participação de mais de 80 países, apontam que estamos abaixo de países que têm um Produto Interno Bruto (PIB) inferior ao nosso, como Uruguai, Chile, Costa Rica, Peru e Colômbia (MORENO, 2019).

Com essa grave deficiência na aprendizagem, a Matemática já alcançou o status de vilão pois, segundo Sementkowski e Brandes (2009), é a disciplina que mais reprova, podendo ser esse um dos motivos do abandono escolar por parte de alguns alunos. De acordo com Sadovsky (2010), para resgatar o comprometimento com a escola, é preciso que o discente esteja motivado a estar junto com seus pares para evoluir e não desanimar. Nesse contexto, o uso dos dispositivos móveis com seus aplicativos torna-se um dos recursos que pode ser utilizado pelos estudantes, pois além de possibilitar uma conexão entre eles, também permite estreitar os laços que os une com o professor em uma amplitude jamais imaginada.

Entre os aplicativos dos dispositivos móveis, está o WhatsApp que, além de ser o maior aplicativo de mensagens da atualidade, vem sendo utilizado por professores pesquisadores na área de ensino. Para alguns, usar esse aplicativo traz desvantagens como falta de privacidade do professor com relação ao seu número de celular, sobrecarga de trabalho, pois, em geral, ele responde as mensagens fora do horário de aula. Para outros, esse aplicativo tem como vantagem auxiliar no processo de ensino aprendizagem. Diante disso, este artigo tem como objetivo apresentar o resultado de uma pesquisa que teve como finalidade avaliar a contribuição desse aplicativo no ensino, mais especificamente, no esclarecimento de dúvidas dos conteúdos de Matemática propostos nas atividades de lição de casa.

A importância desse resultado está em auxiliar outros professores que se interessam pelo uso dos recursos tecnológicos e, assim, incentivá-los a utilizarem esse aplicativo (WhatsApp) como canal de esclarecimento de dúvidas, ou mesmo para que estimulem seus alunos a criarem um grupo de estudos entre eles, pois devido à grande quantidade de conteúdos estudados em sala de aula, ou por sentirem vergonha ao não entenderem as explicações, alguns alunos levam as dúvidas para casa, prejudicando a aprendizagem. 


\section{Ensino da Matemática e as Tecnologias}

A Matemática no contexto escolar ocupa um status diferenciado das outras áreas do conhecimento. Esse status pode ser observado na Base Nacional Comum Curricular (BNCC) quando o Ministério da Educação definiu as áreas de conhecimento para o Ensino Fundamental Anos Finais em: Linguagens (Língua Portuguesa, Inglês, Arte e Educação Física), Ciências da Natureza (Ciências), Ciências Humanas (História e Geografia) e Matemática (BRASIL, 2016). Essa separação não implica que a Matemática não deva estar relacionada com os outros conteúdos, pois, de acordo com os Parâmetros Curriculares Nacionais (BRASIL, 1998), um dos objetivos dessa disciplina no Ensino Fundamental é levar o estudante a estabelecer conexões entre os temas matemáticos e os conhecimentos de outras áreas do currículo.

Para que o aluno consiga estabelecer essas conexões, é importante que o professor, ao ensinar Matemática, tenha cuidado com a forma como ele aborda seus conteúdos. Segundo Vieira (2012), sua forma de abordagem pode ou não contribuir para manter a crença dos estudantes quanto à dificuldade de aprendê-la e consequentemente de realizar sua conexão com as outras áreas do conhecimento.

As dificuldades dos estudantes quanto à aprendizagem de Matemática já foi investigada por vários pesquisadores da área e, de acordo com Sementkowski e Brandes (2009), há uma dicotomia quanto a sua origem: para os alunos, elas decorrem da abordagem do professor, em contrapartida esses consideram que o desinteresse é a raiz do problema.

Nessa dicotomia, o ensino da Matemática torna-se um desafio para a gestão escolar, pois essa deve ser mediadora desses dois conflitos. Sadovsky (2010) sinaliza que esta tarefa não é fácil, devido ao desinteresse e à resistência do aluno em não querer aprender a disciplina. Uma forma de minimizar esse problema é a escola investir em estratégias de ensino diferenciadas, dentre elas, as que envolvem o uso das tecnologias. Silva e Martinez (2017) apontam que o uso de estratégias diversificados pelo professor, além de melhorar a aprendizagem, poderá proporcionar uma melhoria na relação entre professor/aluno e entre a classe no geral.

Para Chinellato, Domingues e Romanello (2016), o uso das tecnologias requer conhecimento dos seus recursos pelos professores. Dentre esses recursos tecnológicos, estão os smartphones e seus aplicativos. Atualmente, o que se observa nas salas de aula é que os alunos não se desconectam dos seus smartphones, parece que são partes inseparáveis. Assim, o docente deve aproveitar o gosto dos jovens por esses dispositivos móveis e usá-los para a aprendizagem.

Sobre as pesquisas que descrevem o uso dos dispositivos móveis no ensino da Matemática, podemos citar as desenvolvidas por Junquer e Cortez (2011), Quin (2012), Costa et al. (2017), Oliveira e Amaral (2019). Em todos os trabalhos, os resultados evidenciaram, segundo seus autores, que essa união facilitou a aprendizagem dos conteúdos.

Quanto ao uso do aplicativo WhatsApp no ensino, os estudos desenvolvidos por Araújo e Araújo (2016), Schmitz (2016), Schiehl, Martins e Santos (2017), Oliveira e Schimiguel (2018) mostraram que esse aplicativo aumenta o interesse pela Matemática, corroborando para abrir novas conexões na relação ensino-aprendizagem, facilitando a comunicação entre os alunos e o professor, além de contribuir de forma positiva para a compreensão dos conteúdos matemáticos. 
Schmitz (2016), em suas análises, conclui que o uso do aplicativo WhatsApp, o professor entra em contato direto com o aluno para propor, aceitar e encarar desafios juntos. Porém, o autor coloca algumas dificuldades para se usar WhatsApp e uma delas está relacionada ao tamanho da tela dos smartphones, que dificulta a visualização das conversas ou as discussões das atividades. Porém, a versatilidade desses aparelhos, não só como veículo de comunicação, mas também de interação coletiva, supera essa dificuldade. Nessa perspectiva, fica claro que somente o uso da lousa pelo professor não é mais suficiente para manter os alunos interessados em aprender.

\section{Metodologia}

Neste trabalho, adotamos a metodologia de um estudo de caso que, segundo Yin (2010), apresenta diferentes modos de aplicação: explanatórios, descritivos e exploratórios. Nesta pesquisa, optamos pela descrição de uma experiência que foi desenvolvida com 60 alunos de duas turmas do $9^{\circ}$ ano do Ensino Fundamental em uma escola pública da cidade de Votorantim no estado de São Paulo. Essa experiência ocorreu em 5 etapas (Quadro 1).

Quadro 1 - Descrição e objetivos das etapas

\begin{tabular}{|c|c|c|}
\hline Etapas & Descrição & Objetivos \\
\hline 1 & $\begin{array}{l}\text { Dividir os alunos em grupos. } \\
\text { Resolução de problemas sobre } \\
\text { semelhança de triângulos, relações } \\
\text { métricas em um triângulo retângulo e } \\
\text { relações trigonométricas em sala de aula. } \\
\text { Atividades para casa. }\end{array}$ & $\begin{array}{l}\text { Desenvolver o trabalho em equipe. } \\
\text { Acompanhar e orientar as resoluções de } \\
\text { problemas das atividades nos grupos. } \\
\text { Incentivar a resolução de problemas nas } \\
\text { atividades de lição de casa, para que o aluno } \\
\text { entenda seus processos internos de } \\
\text { aprendizagem. }\end{array}$ \\
\hline 2 & $\begin{array}{l}\text { Discussão dialogada sobre as resoluções } \\
\text { dos problemas propostos na lição de casa. }\end{array}$ & $\begin{array}{l}\text { Entender os caminhos percorridos e as } \\
\text { dificuldades encontradas pelos alunos para } \\
\text { chegar à resolução de cada problema. }\end{array}$ \\
\hline 3 & $\begin{array}{l}\text { Discussão entre professora e alunos sobre } \\
\text { recursos pedagógicos que facilitariam a } \\
\text { aprendizagem dos conteúdos propostos } \\
\text { nos exercícios de lição de casa. } \\
\text { Escolha do recurso pedagógico. }\end{array}$ & $\begin{array}{l}\text { Encontrar soluções para diminuir as } \\
\text { dificuldades encontradas nas resoluções dos } \\
\text { problemas em atividades individuais. }\end{array}$ \\
\hline 4 & $\begin{array}{l}\text { Criação do grupo de WhatsApp pelos } \\
\text { alunos. }\end{array}$ & $\begin{array}{l}\text { Esclarecimento das dúvidas surgidas nas } \\
\text { resoluções dos problemas da lição de casa. }\end{array}$ \\
\hline 5 & Avaliação & $\begin{array}{l}\text { Discutir a utilização do aplicativo WhatsApp } \\
\text { nas resoluções das atividades de lição de casa. }\end{array}$ \\
\hline
\end{tabular}

Fonte: Elaborado pelas autoras (2019).

Neste artigo, descrevemos as etapas 4 e 5 do Quadro 1. A professora também participou do grupo do WhatsApp, porém delimitou um horário para que as discussões fossem possíveis, adequando tempo e espaço para não ter uma sobrecarga de trabalho. 
Os exercícios estavam nos materiais didáticos adotados pela escola e no acervo da biblioteca: Araribá Matemática (Editora Moderna, 2016) ${ }^{1}$, Matemática teoria e contexto (CENTURIÓN; JAKUBOVIC, 2012) e caderno do aluno disponibilizado pela Secretaria Estadual da Educação de São Paulo (SÃO PAULO, 2019).

\section{Resultados da aplicação do WhatsApp}

Inicialmente, foi criado um grupo no WhatsApp para facilitar a comunicação aluno/aluno e professora/aluno. Porém, esses também utilizaram o aplicativo para conversar com a professora quando não podiam comparecer à aula, como pode ser observado na composição de diferentes momentos do diálogo professora/aluno apresentados na Figura 1, mostrando assim uma relação de afetividade. Esta relação é fundamental, pois mostra o interesse do aluno pela aula. Para Alves (2003, p.38): "O olhar de um professor tem um poder de fazer a inteligência de uma criança florescer ou murchar. Ela continua lá, mas se recusa a sair para a aventura de aprender".

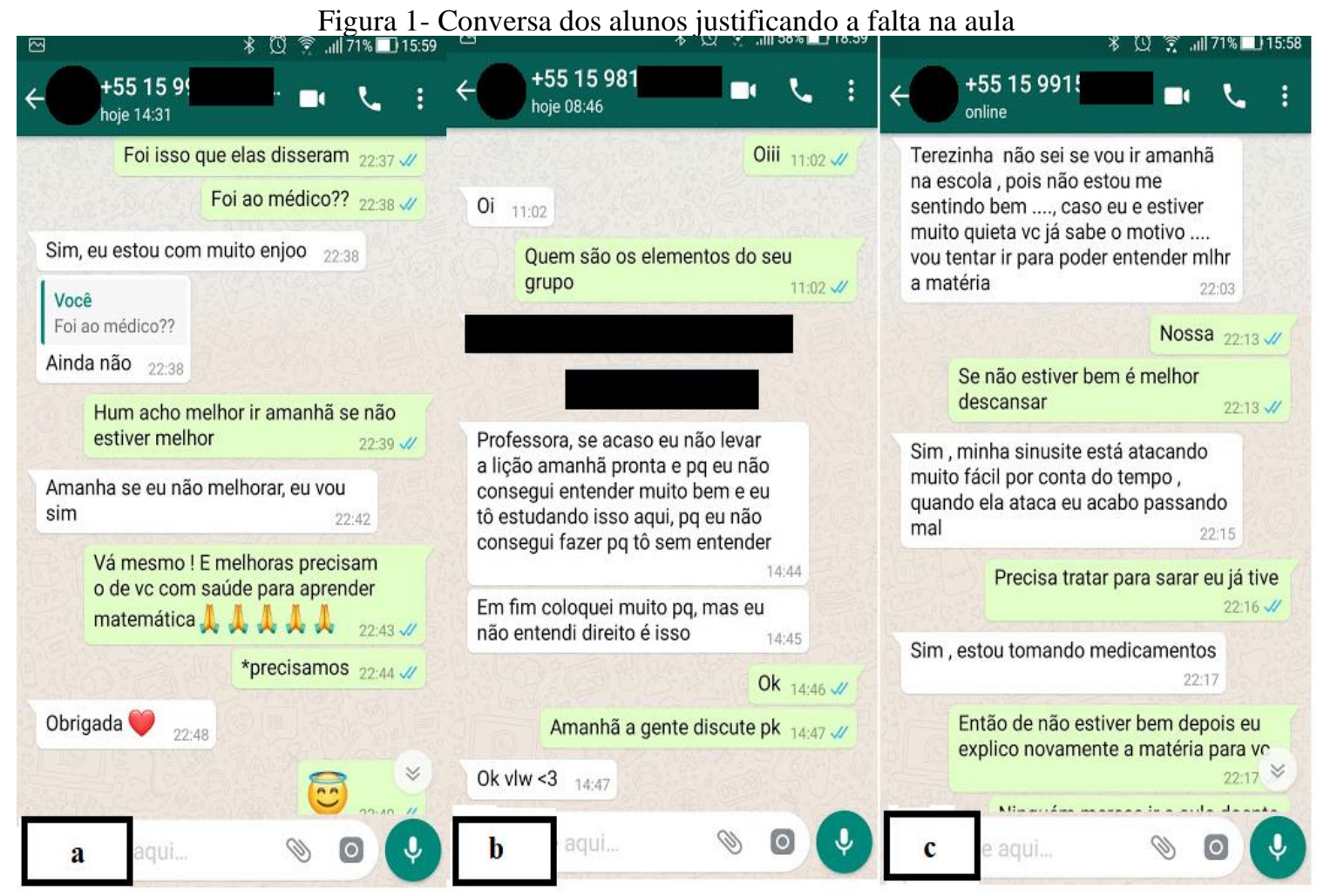

Fonte: Elaborado pelas autoras (2019).

A relação afetiva do aluno com a professora é importante no processo de ensino aprendizagem, pois, segundo Piaget (1995), o desenvolvimento intelectual possui dois componentes: o afetivo e o cognitivo, os quais não são separados, ou seja, a afetividade influencia os processos cognitivos e estes, por sua vez, influenciam a atividade afetiva do estudante.

\footnotetext{
${ }^{1}$ Esse livro não tem um autor definido. É uma obra coletiva concebida, desenvolvida e produzida pela editora Moderna.
} 
Para Tassoni (2000), as interações sociais e as relações entre alunos, professores, conteúdos escolares, livros, escrita etc. não acontecem puramente no campo cognitivo. Existe uma base afetiva permeando essas relações que influenciam no desempenho escolar.

Por ser a escola o local onde o aluno passa a maior parte da sua vida, ela deve favorecer a afetividade em todos os aspectos cognitivos para estimular a criatividade, a imaginação e a aprendizagem. Como descreve Moran (2006), alunos motivados facilitam o processo de ensinoaprendizagem tornando-se parceiros do professor.

Essa parceria é importante no ensino da Matemática porque, de acordo com Chacón (2003), essa é cercada de crenças que estão vinculadas às experiências pessoais e tem fortes componentes afetivos. Desta forma, o professor deve se conscientizar de que as reações emocionais estão ligadas às interações em sala de aula e, consequentemente, na aprendizagem.

Entretanto, pesquisas têm mostrado que a aprendizagem transcende as salas de aula e que isso também auxilia o aluno a construir o seu conhecimento. Resende e Mesquita (2013), ao realizarem uma investigação com professores e alunos sobre as principais dificuldades percebidas no processo de ensino e aprendizagem de Matemática, evidenciaram que o estudo fora do horário de aula oportuniza o aluno a testar seus conhecimentos, validando assim o assimilado na escola, e que este estudo deve ser motivado pelos professores para modificar hábitos e crenças relacionadas à aprendizagem.

Neste trabalho, incentivou-se o estudo de Matemática além da sala de aula a partir de esclarecimentos de dúvidas para a resolução de exercícios propostos na lição de casa. Os alunos, em suas casas, estudavam o conteúdo e, ao ter uma dúvida, entravam no WhatsApp e solicitavam auxílio de seus colegas, quando não conseguiam o esclarecimento dessas dúvidas, solicitavam o auxílio da professora no horário já combinado.

A Figura 2 mostra uma composição de diferentes momentos do diálogo professora/aluno quanto às dúvidas na resolução de exercícios sobre semelhança de triângulos (2a) e relações trigonométricas ( $2 \mathrm{~b}$ e $2 \mathrm{c}$ ). Na Figura 2a, podemos observar que o aluno não encontra a resposta do exercício e, então, apresenta sua dúvida à professora com o objetivo de entender o que está errando.

A dificuldade na resolução dos exercícios pode, muitas vezes, desanimar os alunos. Porém, esse interesse dos mesmos em querer saber o porquê de estar errando é importante para entender seus processos cognitivos e, assim, sanar dúvidas apresentadas, o que foi proporcionado pelo uso do WhatsApp, corroborando com as pesquisas de (SCHIEHL;MARTINS; SANTOS, 2017) e (OLIVEIRA ; SCHIMIGUEL, 2018).

$\mathrm{Na}$ Figura 2b, o aluno solicita auxílio da professora para resolver um exercício sobre relações trigonométricas. Nesse exercício, o aluno deveria calcular o valor da hipotenusa utilizando a relação do seno, pois foi dado o valor do cateto oposto de 4,7 e o valor do seno de $70^{\circ}$ sendo 0,94 . Entretanto, ele não conseguia achar o resultado, porque estava multiplicando 4,7 por 0,94 e, para sua resolução, ele deveria dividir 4,7 por 0,94. Ao escrever para o aluno, mostrando onde estava se confundindo, o mesmo ainda não acreditou e foi necessário que a professora mostrasse na calculadora (Figura 2c) o resultado da divisão.

Segundo Booth (2003), essa dificuldade apresentada pelo aluno em resolver a álgebra pode estar relacionada a problemas em aritmética que não sofreram uma intervenção por parte do professor ou mesmo que não foram corrigidas. Assim, isso reforça a importância de atividades em que o professor consiga intervir na aprendizagem, corrigindo as lacunas que os estudantes possam apresentar no Ensino Básico. 
Figura 2- Dúvidas de dois alunos na resolução de exercícios de Matemática
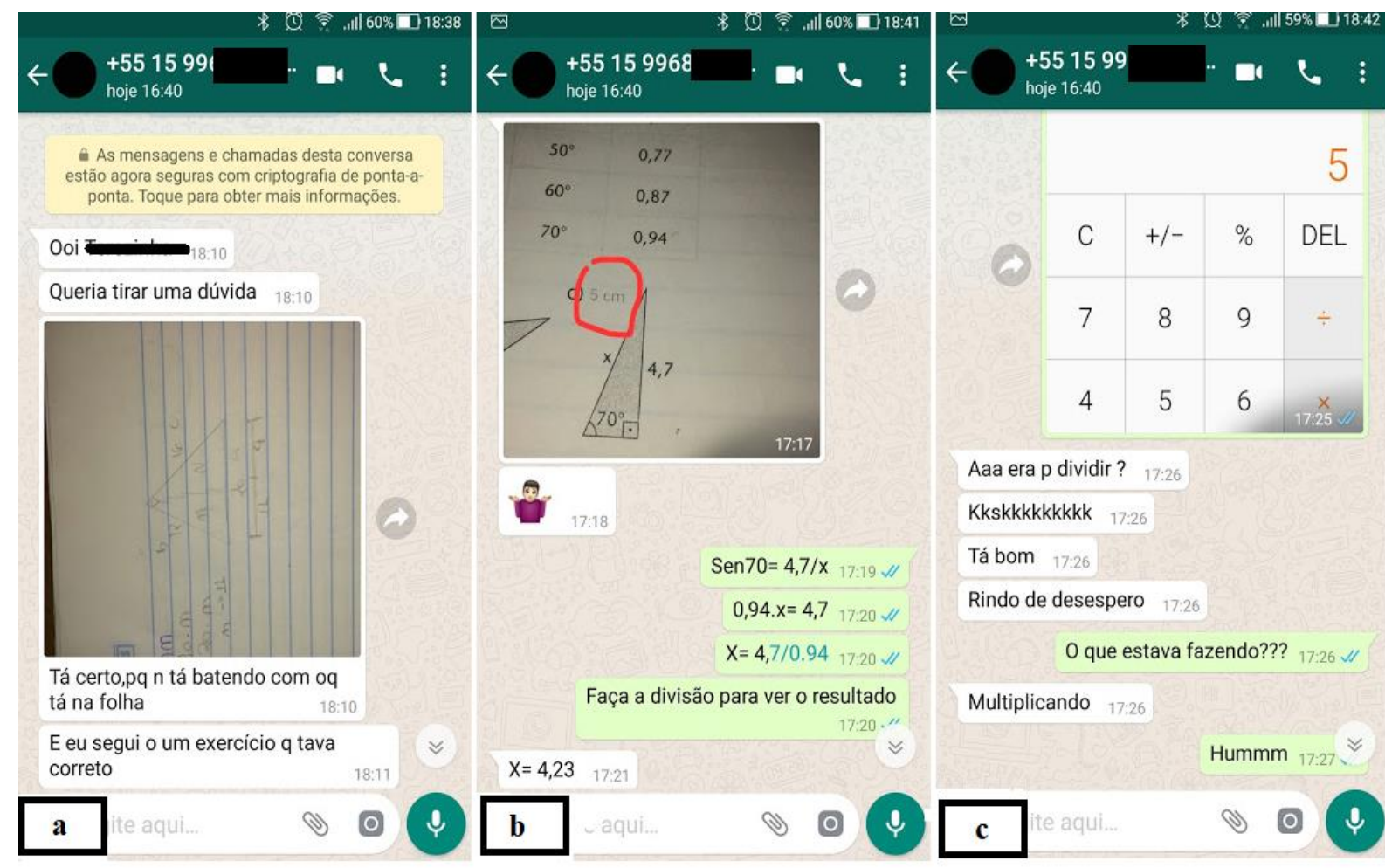

Aaa era p dividir ? $17: 26$

Kkskkkkkkkkk 17:26

Tá bom

Rindo de desespero

O que estava fazendo??

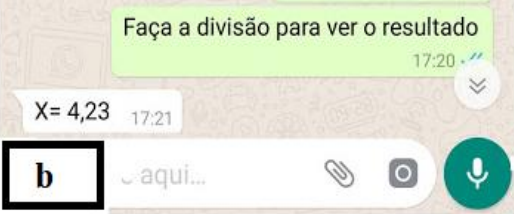

Multiplicando

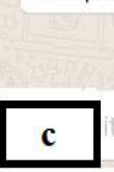

do $17: 26$

Fonte: Elaborado pelas autoras (2019).

Os erros cometidos pelos alunos durante as solicitações de esclarecimentos das dúvidas foram, principalmente, a realização incorreta de operações básicas de matemática e a não compreensão de conceitos. Como pode ser observado na Figura 2, esses erros evidenciaram que, além da dificuldade em operações básicas de matemática, os alunos não apresentaram uma relação conceitual esclarecida sobre a geometria.

Desta forma, tal observação nos faz refletir sobre a nossa prática, uma vez que, durante as atividades desenvolvidas em sala de aula, muitas vezes não percebemos as dificuldades apresentadas pelos alunos, evidenciando assim que devemos nos ater a este fato, pois os alunos não podem finalizar uma etapa dos estudos sem aprender esses conhecimentos. Contudo, ao final da atividade, acreditamos que conseguimos sanar as lacunas na aprendizagem em Matemática apresentadas pelos discentes.

$\mathrm{Na}$ escola, temos que atender diversos alunos e, muitas vezes, os introvertidos acabam levando as dúvidas para casa. Esse comportamento foi observado quando o discente mais tímido da sala solicitou esclarecimentos das dificuldades que estava encontrando, buscando o auxílio da professora (Figura 3).

Em sala de aula, esse aluno dificilmente expõe suas dificuldades, entretanto, conseguiu, pelo WhatsApp, interagir com a professora e, ao esclarecer suas dúvidas, o mesmo comemorou quando acertou, comentando, "essa eu acertei" (Figura 3b). Esse comportamento corrobora com o que foi observado na pesquisa de Schiehl, Martins e Santos (2017) sobre a contribuição do WhatsApp de forma positiva, para que os alunos se envolvessem em atividades que antes não tinham vontade em aprender. 
Figura 3- Composição de diferentes momentos do diálogo professora/aluno

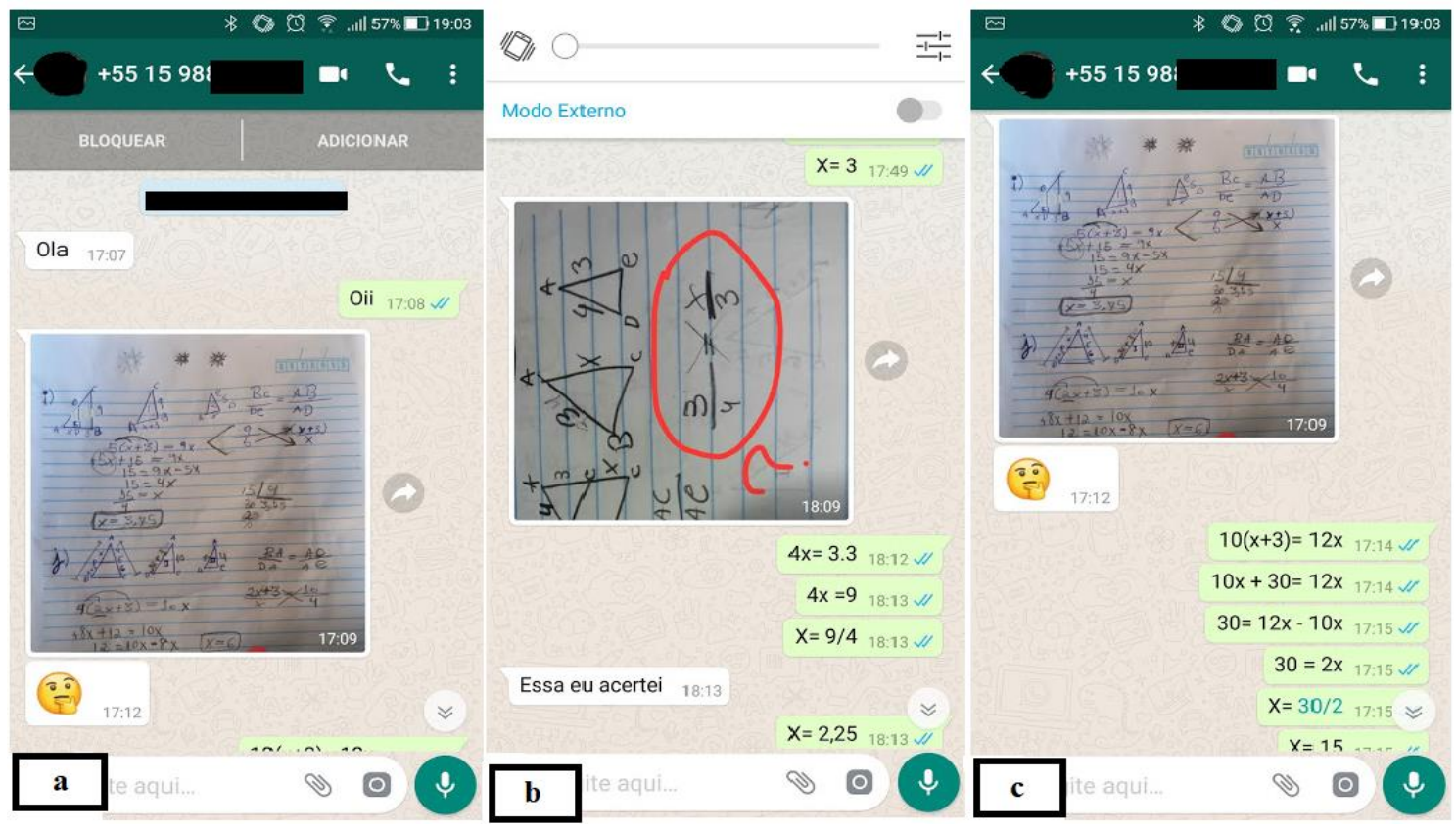

Fonte: Elaborado pelas autoras (2019).

Ao término dessa experiência, os alunos foram questionados sobre a utilização desse aplicativo como canal de esclarecimento de dúvidas. Assim, $75 \%$ dos estudantes responderam que gostaram, principalmente por terem um canal de comunicação a mais com seus colegas e com a professora para que as dúvidas fossem esclarecidas, pois o tempo em sala de aula pode não ser suficiente. A Figura 4 apresenta dois depoimentos de alunos quanto ao uso do WhatsApp como canal de esclarecimento de dúvidas.

Figura 4- Diálogos sobre o novo canal de comunicação

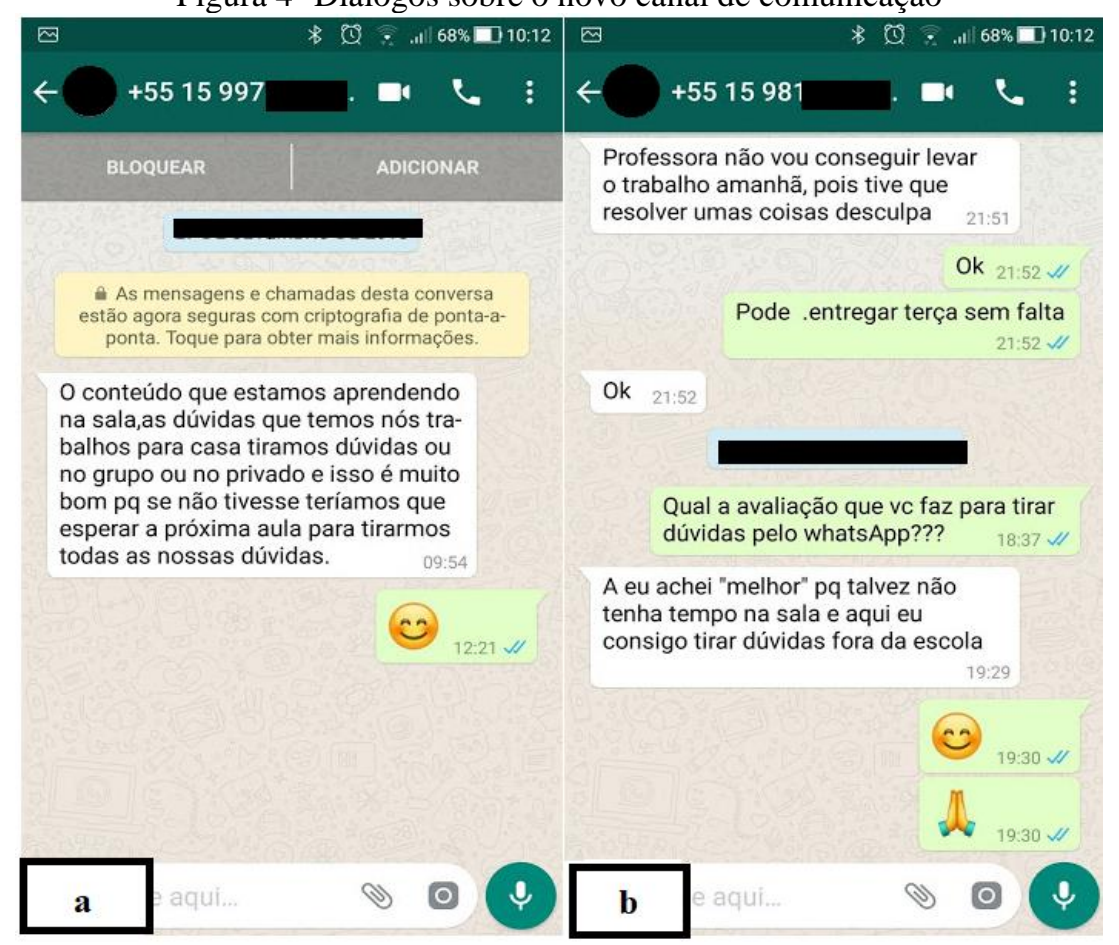

Fonte: Elaborado pelas autoras (2019). 
Os resultados dessa avaliação, por parte dos alunos, mostraram que a utilização do aplicativo foi positiva, houve tempo suficiente para dialogarem com os colegas, com a professora, criarem laços afetivos que possibilitaram uma aprendizagem mais significativa, além de auxiliá-los no esclarecimento de dúvidas. Um resultado semelhante foi observado por Bouhnik e Deshen (2014) com alunos do ensino médio. De acordo com esses autores, o uso do WhatsApp teve como vantagens educacionais a criação de um ambiente agradável e de maior proximidade entre os discentes, e a disponibilidade dos professores em interagir além do horário das aulas.

Algumas experiências que têm origem em sala de aula muitas vezes não conseguem se manter e acabam por se tornar obsoletas ou repetitivas, mas, no caso do WhatsApp, não parece ter o mesmo desfecho. Recentemente, o estado de São Paulo suspendeu no mês de março as atividades escolares por tempo indeterminado. Esta medida se deve ao combate da pandemia de COVID-19 (SÃO PAULO, 2020). Entretanto, não foram somente as escolas que fecharam, mas vários serviços como comércios, shopping, bares etc. Somente os serviços essenciais como transportes, supermercados e serviços de saúde ficaram abertos. Desta forma, com os alunos em casa e em isolamento, algumas escolas providenciaram atividades virtuais. O principal meio de comunicação com os pais e professores passou a ser os grupos de WhatsApp (Figura 5), tanto na esfera informativa quanto para enviar links nos quais as atividades estarão disponíveis.

Nesse momento de pandemia, este trabalho auxiliou esses alunos, pois como eles já utilizavam o WhatsApp, foi mais fácil a comunicação com a professora e a continuação das atividades escolares em casa. Ao escrever este artigo, jamais imaginávamos a utilização desta ferramenta com tamanha magnitude no cenário da nossa escola.

Figura 5- Diálogos entre professora e alunos em tempos de isolamento

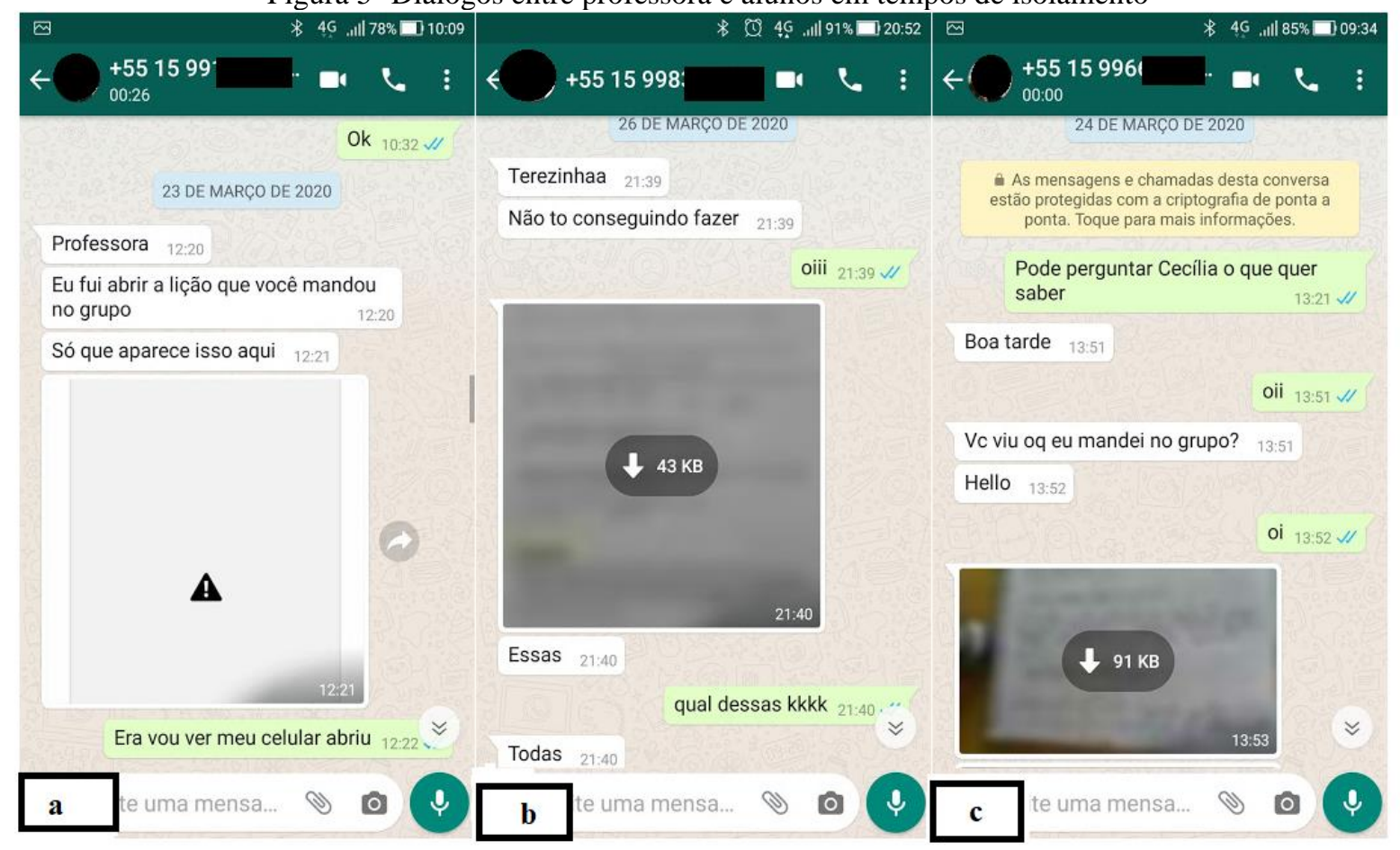

Fonte: Elaborado pelas autoras (2020).

Assim, em tempos de quarentena, atividades como esta reforçam a ideia de Schmitz (2016), que descreve que com o uso do aplicativo WhatsApp, o professor usa o contato direto 
com o aluno para propor, aceitar e encarar desafios juntos. Em um cenário difícil de idealizar, sigamos o conselho de Demo (2011, p. 23), para quem "ser professor é cuidar que o aluno aprenda".

\section{Conclusão}

Esse artigo teve como objetivo avaliar a contribuição do aplicativo WhatsApp no ensino da Matemática. Os resultados observados evidenciaram que este aplicativo corroborou em: auxiliar os alunos a esclarecerem suas dúvidas; melhorar a relação aluno/aluno; favorecer os mais tímidos a exporem suas dúvidas sem constrangimentos; facilitar o processo de comunicação com a professora; ajudar na percepção dos erros conceituais desses em relação à Matemática.

Esses erros nos levaram a replanejar as estratégias de ensino utilizadas em nossas aulas. E, nesse replanejamento, o uso das tecnologias se fez presente, uma vez que estas vêm adquirindo cada vez mais espaços em salas de aula. Entre as tecnologias presentes no nosso replanejamento, estão os smartphones com seus aplicativos, pois percebemos que o WhatsApp motivou os alunos a estudarem Matemática.

Desta forma, pode-se concluir que o uso desse aplicativo foi uma experiência exitosa, uma vez que, mesmo após o término, os alunos continuam utilizando o WhatsApp não só para tirar dúvidas sobre as atividades de lição de casa, mas também, em decorrência da pandemia de Covid-19 que estamos enfrentando neste momento, os estudantes permanecem usando o grupo para sanar as suas dificuldades nas aulas virtuais e se comunicando.

É importante enfatizar que, quando o professor fizer parte do grupo, deve esclarecer sobre sua carga horária, ou seja, limitar o tempo de acordo com sua disponibilidade. É preciso manter o bom senso para não atrapalhar a vida pessoal de ambos e não sobrecarregar o professor.

\section{Referências}

ALVES, R. Por uma educação romântica. Campinas: Papirus, 2003.

ARAÚJO, J. P.; ARAÚJO, J. P. Uso do aplicativo WhatsApp na relação ensino-aprendizagem da matemática: uma proposta educomunicativa. In: ENCONTRO NACIONAL DE EDUCAÇÃO MATEMÁTICA, 12, 2016. São Paulo, SP. Anais... São Paulo, 2016. Disponível em: http://www.sbembrasil.org.br/enem2016/anais/pdf/5101_3349_ID.pdf. Acesso em: 14 dez. 2019.

BOOTH, R. L. Dificuldades das crianças que se iniciam na álgebra. In: COXFORD, A. F.; SHULTE, A. P. (Org.). As ideias da álgebra. São Paulo: Atual, 2003.

BOUHNIK, D.; DESHEN, M. WhatsApp goes to school: Mobile instant messaging between teachers and students. Journal of Information Technology Education: Research, v. 13, p. 217-231, 2014. 
BRASIL. Ministério da Educação. Secretaria da Educação Básica. Base nacional comum curricular. Brasília: DF, 2016. Disponível em: http://basenacionalcomum.mec.gov.br/. Acesso em: 19 dez. 2020.

BRASIL. Secretaria de Educação Fundamental. Parâmetros curriculares nacionais: matemática / Secretaria de Educação Fundamental. Brasília: MEC/SEF, 1998.

CHACÓN, I. M. G. Matemática emocional: os afetos na aprendizagem Matemática. Porto Alegre: Artmed, 2003.

CHINELlATO, T. G.; DOMINGUES, N. S; ROMANELLO, L. A. O uso de aplicativos do google play e atividades investigativas em educação matemática. In: ENCONTRO NACIONAL DE EDUCAÇÃO MATEMÁTICA, 12., 2016, São Paulo. Anais [...]. São Paulo, 2016. Disponível em:

http://www.sbembrasil.org.br/enem2016/anais/pdf/5101_3349_ID.pdf. Acesso em: 14 dez. 2019.

COSTA, J. F. et al. O ensino de Matemática e o uso do celular: a aprendizagem da alimentação saudável dos estudantes do ensino médio. In: EDUCERE, 13., 2017, Curitiba. Anais [...]. Curitiba, 2017. Disponível em: http://educere.bruc.com.br/arquivo/pdf2017/23139_12148.pdf. Acesso em: 10 dez. 2019.

DEMO, P. Pensando e fazendo educação: Inovações e experiências educacionais. Brasília: Liber Livro, 2011.

JUNQUER, A. C. L; CORTEZ, E. A. S. As diversas mídias e o uso do celular na sala de aula. Leitura: Teoria \& Prática, v.29, n.56, p. 60-66, 2011.

OLIVEIRA, T. M. R.; AMARAL, C. L. C. O uso do aplicativo Lensoo Create na recuperação da aprendizagem do processo de avaliação processual em matemática. Em Teia. Revista de Educação Matemática e Tecnológica Iberoamericana, v.10, n.2, p.1 -15, 2019.

OLIVEIRA, J. C.; SCHIMIGUEL, J. WhatsApp: aplicativo facilitador no ensino da matemática. Revista Estudos Aplicados em Educação, v.3, n.5, p.27-41, 2018.

MORAN, J. M. et al. Novas tecnologias e mediação pedagógica. Campinas: Papirus, 2006.

MORENO, A. C. Pisa 2018: dois terços dos brasileiros de 15 anos sabem menos que o básico de matemática. Portal G1, Globo, 2019. Disponível em:

https://g1.globo.com/educacao/noticia/2019/12/03/pisa-2018-dois-tercos-dos-brasileiros-de15-anos-sabem-menos-que-o-basico-de-matematica.ghtml. Acesso em: 02 jan. 2020.

PIAGET, J. Abstração reflexionante: relações lógico-elementares e ordem das relações espaciais. Porto Alegre: Artes Médicas, 1995.

QUINN, C. Designing mLearning. Tapping into the mobile revolution for organizational performance. San Francisco, CA: Pfeiffer, 2012. 
RESENDE, G.; MESQUITA, M. G. B. F. Principais dificuldades percebidas no processo ensino-aprendizagem de matemática em escolas do município de Divinópolis, MG. Educação Matemática Pesquisa, v.15, n.1, p. 199-222, 2013.

SADOVSKY, P. O ensino de matemática hoje: enfoques, sentidos e desafios. 1. Ed. São Paulo: Ática,2010.

SÃO PAULO. Secretaria de Educação. $9^{\circ}$ Ano. Ensino Fundamental Anos Finais. Caderno do aluno, 2019.

SÃO PAULO. Secretaria do Estado de Educação de São Paulo. Aulas da rede estadual de SP começam a ser suspensas a partir desta segunda-feira. 2020. Disponível em: https://www.educacao.sp.gov.br/noticias/aulas-da-rede-estadual-de-sp-comecam-sersuspensas-partir-desta-segunda-feira/. Acesso em 27 mar 2020.

SCHIEHL, E. P.; MARTINS, L. P. R.; SANTOS, L. M. WhatsApp como uma ferramenta de apoio na construção do conhecimento de sequências numéricas no primeiro ano do Ensino Médio. Revista Tecnologias na Educação. Ano 9, n.19, p. 1-12, 2017.

SCHMITZ, N. O uso do telefone celular com o aplicativo WhatsApp como ferramenta no ensino de matemática. 2016. 74 f. Dissertação (Mestrado Profissional em Matemática em Rede Nacional). Universidade Tecnológica Federal do Paraná, Pato Branco, 2016.

SEMENTKOWSKI, V.; BRANDES, L. A. A Matemática no contexto escolar. ÁGORA: Revista de Divulgação Científica. v.16, n. 2, p.88-93, 2009.

SILVA, R. S.; MARTINEZ, M. L. S. Dificuldades na matemática básica: o processo de ensino-aprendizagem para a vida. In: EDUCERE, 13., 2017. Curitiba. Anais [...] Curitiba, 2017. Disponível em: http://educere.bruc.com.br/arquivo/pdf2017/24274_13230.pdf. Acesso em: 10 dez. 2019.

TASSONI, E. C. M. Afetividade e aprendizagem: a relação professor-aluno. In: REUNIÃO ANUAL DA ANPED, 23., 2000. Caxambú. Anais [...]. Caxambú, 2000. Disponível em: http://23reuniao.anped.org.br/textos/2019t.pdf. Acesso: 03 dez. 2019.

VIEIRA, A. C. Educação Matemática no Brasil: Problemas e possíveis soluções. In: Escola de Inverno de Educação Matemática, 3., 2012. Santa Maria. Anais [...]. Santa Maria, 2012. Disponível em: http://w3.ufsm.br/ceem/eiemat/Anais/arquivos/CC/CC_Vieira_Andrea_Cristina.pdf. Acesso em: 02 dez. 2019.

YIN, R.K. Estudo de Caso: planejamento e métodos. Tradução: Ana Thorell. Porto Alegre: Bookman. 2010.

Recebido em março de 2020.

Aprovado em maio de 2020. 